\title{
Free radical problems of the newborn
}

\section{By D. P. R. Muller, Institute of Child Health, 30 Guilford Street, London $W C \mathrm{I}$ I $E H$}

Oxygen-derived free radical species have been implicated in a rapidly increasing number of disease processes (Bulkley, r983; Halliwell \& Gutteridge, 1985a). They probably play a major role in any disease process that involves hyperoxygenation, ischaemia (particularly when followed by reperfusion) and tissue inflammation. $\mathrm{O}_{2}$-derived free radicals are also the primary means by which neutrophils kill bacteria, radiation injures malignant and normal tissue, and by which many drugs, carcinogens and other toxic agents exert their effects. It is, therefore, not surprising that cells and tissues are protected against oxidizing free radicals by a range of antioxidant mechanisms which include enzymes such as superoxide dismutase ( $E C$ I.I5.1.1), glutathione peroxidase ( $E C$ I.1 1.1.9) and catalase ( $E C$ I.I I.1.6), and small molecules such as ascorbic acid, glutathione and $\alpha$-tocopherol (Deneke \& Fanburg, I980; Halliwell \& Gutteridge, I985 $b$ ).

The newborn is particularly susceptible to $\mathrm{O}_{2}$-derived free radicals, because at birth an infant abruptly enters a relatively hyperoxic extrauterine environment with the alveoli being exposed to an $\mathrm{O}_{2}$ tension approximately five times greater than that during intrauterine development. The situation is further exacerbated in many small premature infants where as part of management for the respiratory distress syndrome they are exposed to increased concentrations (up to $100 \%$ ) of $\mathrm{O}_{2}$.

The present paper will review current information regarding the status and development of antioxidant systems in the newborn, will consider those conditions in which free radicals have been implicated and will critically examine the potential role of antioxidant therapy in these conditions.

\section{Status and development of antioxidant systems in the newborn}

For obvious reasons most of the work on the status and development of antioxidant systems in the newborn has been obtained from the experimental animal. The lung and the eye have been most extensively studied as these are the organs which come into direct contact with $\mathrm{O}_{2}$ and are also associated with conditions (bronchopulmonary dysplasia and retrolental fibroplasia respectively) which have been related to free radical damage.

The exact mechanism(s) by which oxidant damage occurs in the newborn is not clear but peroxidation of membrane lipids has been proposed as an important mechanism. Among the products of the in vivo peroxidation of unsaturated fatty acids are the volatile hydrocarbons, ethane and pentane. These are eliminated in expired air and provide a measure of in vivo lipid peroxidation (Riely et al. 1974; 
Dumelin \& Tappel, I 977). In a recent study, Wispe et al. (1985) reported that the excretion of these hydrocarbons was increased approximately tenfold in infants (mean age ro d) compared with adults. This suggested an increased rate of lipid peroxidation in infants and confirmed the findings of McCarthy et al. (1984) of increased serum concentrations of malondialdehyde (another measure of lipid peroxidative damage) in newborn infants compared with adults. This increased rate of lipid peroxidation could result from a number of factors such as the sudden increase in $\mathrm{O}_{2}$ tension in tissues which occurs at birth, from a reduced activity and concentration of the various antioxidants, or from differences in the fatty acid composition of membrane lipids.

The pre- and postnatal development of the antioxidant enzyme systems have been studied in the lung from the rabbit (Autor et al. 1976; Frank \& Groseclose, 1984), rat (Autor et al. 1976; Yam et al. 1978a; Gerdin et al. 1985) and human (Autor et al. 1976). In general a consistent pattern of development has been observed with significant increases in activities just before and after birth. This prenatal increase of activity would tend to protect the lung from hyperoxia at the time of birth. The newborn animal, in contrast to the adult, is able to adapt to hyperoxia. Thus exposure of lungs from newborn animals to increased $\mathrm{O}_{2}$ concentrations results in an increase in enzyme activity (Autor et al. 1976; Yam et al. 1978b; Wender et al. 1981; Warshaw et al. 1985).

With the exception of vitamin $\mathrm{E}$ ( $\alpha$-tocopherol), the major antioxidants (enzymes and small molecules) are water-soluble. Vitamin $\mathrm{E}$ is the only well-recognized, lipid-soluble, secondary chain-breaking antioxidant (Burton et al. 1983). It is generally considered that the vitamin $\mathrm{E}$ status of the newborn is reduced compared with that of the adult. Many studies have documented reduced serum concentrations of the vitamin in the newborn (Straumfjord \& Quaife, I 946; Wright et al. 1951; Leonard et al. 1972). Initially it was thought that this resulted from impaired permeability of the placenta to $\alpha$-tocopherol but it is now thought to be a function of a reduced transport capacity in the blood of the neonate. Thus Haga et al. (1982) reported that the ratio, serum concentrations of $\alpha$-tocopherol: low-density lipoprotein (a major carrier of $\alpha$-tocopherol) is constant and similar in cord and maternal blood. As vitamin $\mathrm{E}$ is a lipid-soluble antioxidant it may be more relevant to express concentrations per lipid and when total body tocopherol is related to total body lipid the ratio is similar for the fetus, newborn and adult (Dju et al. 1952; Bell \& Filer, 1981). It is therefore questionable whether vitamin $\mathrm{E}$ status is in fact reduced in the newborn.

\section{Possible role for vitamin $E$ in the newborn}

The simplest way of altering the antioxidant status of the newborn is by administration of vitamin E supplements, and the use of prophylactic administration of the vitamin has been the subject of considerable debate over recent years. The proposed clinical effects of vitamin $E$ in the newborn can be divided into those that are physiological and pharmacological. Physiological effects include the prevention of haemolytic anaemia, whereas pharmacological doses of 
vitamin $E$ have been suggested for the treatment of conditions such as bronchopulmonary dysplasia, intraventricular haemorrhage and retrolental fibroplasia. The possible role of vitamin $\mathrm{E}$ in these conditions will be examined.

\section{Physiological effects}

Haemolytic anaemia. Hassan et al. (1966) reported a clinical syndrome in premature infants comprising oedema, skin lesions and a haemolytic anaemia which was associated with a deficiency of vitamin $E$, and which disappeared following administration of the vitamin. This report was quickly confirmed by others (e.g. Oski \& Barness, 1967; Ritchie et al. 1968). Since then numerous studies have appeared which have investigated the effect of prophylactic vitamin $E$ on the prevention of anaemia in the neonate. These studies, which have been reviewed by Bell \& Filer ( $198 \mathrm{I}$ ), have given conflicting results. Their interpretation is, however, complicated by other variables in addition to vitamin $E$ intake, such as the dietary content of polyunsaturated fatty acids and iron, the vitamin $\mathrm{E}$ :polyunsaturated fatty acid ratio and the ability of the infant to absorb vitamin $\mathrm{E}$. Reduced erythrocyte survival might also be expected to contribute to the development of hyperbilirubinaemia in the early neonatal period. Studies designed to examine the effect of vitamin $\mathrm{E}$ supplementation on hyperbilirubinaemia have also produced conflicting results (Bell \& Filer, I98r).

As a result of the early studies on the role of vitamin $E$ deficiency in the development of haemolytic anaemia, milk formulas now contain added vitamin $\mathrm{E}$ and an adequate vitamin $\mathrm{E}$ :polyunsaturated fatty acid ratio (greater than 0.6 $\mathrm{mg} / \mathrm{g}$ ). Bell \& Filer (198I) therefore concluded that 'with current feeding practices and formula compositions, vitamin-E-deficiency anaemia is a rare problem, except perhaps in the presence of unusual oxidant stresses. Vitamin E supplementation is not necessary for the prevention of haemolytic anaemia in premature infants'.

\section{Pharmacological effects}

Bronchopulmonary dysplasia. As part of management for the respiratory distress syndrome, premature infants are treated with prolonged artificial ventilation and $\mathrm{O}_{2}$. This therapy has been associated with the development of pathological changes in the lung known as bronchopulmonary dysplasia (Merritt et al. $\mathrm{I} 98 \mathrm{I}$ ) and is a major cause of morbidity and death. Ehrenkranz et al. (1978) reported preliminary results which suggested that intramuscular vitamin $E$ reduced the incidence of bronchopulmonary dysplasia. However, the same group, in a randomized, double-blind prospective trial, failed to confirm their earlier observations (Ehrenkranz et al. 1979) and other investigators have also failed to show that vitamin $\mathrm{E}$ has a protective effect (e.g. Saldanha et al. 1980).

Intraventricular haemorrhage. Intraventricular haemorrhage is the most common finding in the brains of premature babies who die during the ist week of life and is probably one of the most important lesions responsible for handicap in surviving infants. Chiswick et al. ( 1983$)$ reported that vitamin $E$ reduced the incidence of intraventricular haemorrhage in premature infants under 32 weeks of 
gestation. Speer et al. (1984) reported similar results whereas Phelps et al. (1984), in a larger series, were unable to confirm these findings. Prospective studies are currently being undertaken (M. C. Chiswick, personal communication) which should clarify the situation.

Retrolental fibroplasia (retinopathy of prematurity). This retinal disease of the preterm infant was first described by Terry (1942). Subsequent collaborative studies indicated that the condition resulted principally from excessive use of $\mathrm{O}_{2}$ (Kinsey, 1956), although other factors undoubtedly contribute. For example, a recent study (Glass et al. 1985) reported that the degree of illumination in the nursery can alter the incidence of retrolental fibroplasia, with a higher incidence in those infants exposed to bright nursery illumination. Following a reduction in the use of $\mathrm{O}_{2}$, the number of cases of retrolental fibroplasia decreased dramatically in the 1960 s but was associated with an increased mortality and morbidity particularly in infants with respiratory distress syndrome. In recent years an increase in the survival of low-birth-weight infants has again led to an increased incidence of the condition. Owens \& Owens (1949) were the first to suggest that prophylactic vitamin E supplements could reduce the incidence and severity of retrolental fibroplasia but at that time other workers were unable to repeat their findings. More recently, Johnson et al. (1974), in a controlled but non-random study, reported a significant decrease in severity of the disease in infants who received vitamin $\mathrm{E}$. This prompted a number of independent, double-blind, randomized controlled trials which have been reviewed by Phelps (1982). Two of these studies (Hittner et al. 1981; Finer et al. 1982) came to broadly similar conclusions; that administration of vitamin $\mathrm{E}$ (oral and intramuscular respectively) reduced the severity but not the overall incidence of retrolental fibroplasia. Phelps (1982), however, urged caution in the interpretation of these results as she pointed out that misleading conclusions can be drawn from the occurrence of low-incident events.

Phelps (I982) estimated that in the US, 22000 of the 37000 infants born weighing less than $1500 \mathrm{~g}$ survive, and that of these, $2000(9.5 \%)$ would have severe retrolental fibroplasia and $500(2.5 \%)$ would be blind. The incidence of severe disease in the UK is not accurately known but it is thought to be considerably less than that reported for the US (A. R. Fielder, personal communication). Thus if prophylactic vitamin $\mathrm{E}$ is given to all premature infants a very large percentage of infants (approximately $90 \%$ in the US and more than $90 \%$ in the UK) would be given the vitamin who would not develop the severe form of the condition. This is acceptable if one can be certain that such supplementation was completely safe or that the benefits strongly outweigh the risks. Reports are, however, now appearing which suggest that there may be risks associated with the prophylactic administration of vitamin $E$ to the premature infant and these will now be discussed. 


\section{Possible risks associated with vitamin $E$ administration}

\section{Necrotizing enterocolitis and sepsis}

Necrotizing enterocolitis is a condition which results in widespread intestinal necrosis and frequently leads to perforation of the bowel and peritonitis. It has a high mortality and correlates with immaturity, degree of illness and almost always with feeding. It, therefore, affects the same babies who are at risk of developing retrolental fibroplasia and who may be given oral feeds specifically to incorporate oral vitamin $E$ supplements. There have recently been two reports which suggest that there is an increased incidence of necrotizing enterocolitis in infants given vitamin E supplements. Finer et al. (1984), in a retrospective study of their patients who were given the vitamin to reduce the severity of retrolental fibroplasia, found a significant increase in the incidence of necrotizing enterocolitis in infants weighing less than $1500 \mathrm{~g}$ who were given oral vitamin $\mathrm{E}$. They suggested that this resulted from the hyperosmolarity of the oral preparation used. Johnson et al. (1985), however, used an intramuscular preparation of vitamin $\mathrm{E}$ in a prospective study and also reported a significantly increased incidence of necrotizing enterocolitis. They also found a significantly increased incidence of sepsis in the treated group. In the latter study, serum vitamin $E$ tended to reach supranormal concentrations (mean $50 \mathrm{mg} / \mathrm{l}$ ) compared with a normal adult concentration of approximately $8 \mathrm{mg} / \mathrm{l}$. They suggested that these high concentrations resulted in excess antioxidant capacity which impaired the normal $\mathrm{O}_{2}$-dependent antimicrobial defence mechanisms and resulted in an increased susceptibility to infection.

\section{Mortality}

In 1983 an intravenous vitamin E preparation, E-Ferol, was marketed and used pharmacologically for the prevention of retrolental fibroplasia in the US. It was, however, recalled in the following year following the death of thirty-eight infants (Phelps, 1984). The syndrome associated with E-Ferol was described by Lorch et al. (1985) and comprised pulmonary deterioration, thrombocytopenia, liver failure, ascites and renal failure. Eight of fifty-eight infants who had received E-Ferol developed the syndrome and five died. Since discontinuation of the preparation the syndrome disappeared. The mechanism underlying this syndrome appears to be related to the carrier (polysorbate 80 ) used in the preparation rather than to the vitamin E itself (Alade et al. 1986).

\section{Conclusions}

Haemolytic anaemia and oedema associated with a deficiency of vitamin $\mathrm{E}$ in the newborn occurred in the r $960 \mathrm{~s}$, but with modern feeding practices and formula composition it now only presents rarely as a clinical problem. If a deficiency of vitamin $\mathrm{E}$ is suspected as the cause of an unexplained haemolytic anaemia, adequate supplements should be given to achieve and maintain a serum concentration within the normal adult range and a clinical response monitored. 
With regard to the use of prophylactic vitamin E supplements in the premature infant, it does not appear to be of benefit in bronchopulmonary dysplasia. Its role in intraventricular haemorrhage remains to be proven. There does appear to be evidence that vitamin $E$ reduces the severity but not the incidence of retrolental fibroplasia. In view, however, of recent reports of an increased incidence of necrotizing enterocolitis and sepsis associated with vitamin $E$ supplementation, the risk :benefit ratio of prophylactic vitamin $\mathrm{E}$ administration remains to be clarified. We must therefore agree with the recent recommendation of an American Committee on Fetus and Newborn (1985) which concluded 'At this time, however, the Committee regards prophylactic use of pharmacological vitamin E as experimental and cannot recommend that high doses of vitamin $E$ be given routinely to infants weighing less than $\mathrm{I} 500 \mathrm{~g}$ even if such use is limited to infants who require supplemental $\mathrm{O}_{2}$ '.

\section{REFERENCES}

Alade, S. L., Brown, R. E. \& Paquet, A. Jr (I986). Pediatrics 77, 593-597.

Autor, A. P., Frank, L. \& Roberts, R. J. (1976). Pediatric Research ro, $154-158$.

Bell, E. F. \& Filer, L. J. Jr ( 1981 ). American fournal of Clinical Nutrition 34, 414-422.

Bulkley, G. B. (1983). Surgery $94,407411$.

Burton, G. W., Joyce, A. \& Ingold, K. U. (I983). Archives of Biochemistry and Biophysics 221 , $281-290$.

Chiswick, M. L., Johnson, M., Woodhall, C., Gowland, M., Davies, J., Toner, N. \& Sims, D. G. (1983). British Medical fournal 287, 81-84.

Committee on Fetus and Newborn (1985). Pediatrics 76, 315-3i6.

Deneke, S. M. \& Fanburg, B. L. (1980). New England Yournal of Medicine 303, 76-86.

Dju, M. Y., Mason, K. E. \& Filer, L. J. Jr (1952). Etudes Neonatales 1, 49-62.

Dumelin, E. E. \& Tappel, A. L. (1977). Lipids 1 2, 894-900.

Ehrenkranz, R. A., Ablow, R. C. \& Warshaw, J. B. (1979). Fournal of Pediatrics 95, 873-878.

Ehrenkranz, R. A., Bonta, B. W., Ablow, R. C. \& Warshaw, J. B. (1978). New England Fournal of Medicine 299, 564-569.

Finer, N. N., Grant, G., Schindler, R. F., Hill, G. B. \& Peters, K. L. (1982). Lancet i, 1087-1091.

Finer, N. N., Peters, K. L., Hayek, Z. \& Merkel, C. L. (1984). Pediatrics 73, 387-393.

Frank, L. \& Groseclose, E. E. (1984). Pediatric Research 18, 240-244.

Gerdin, E., Tyden, O. \& Eriksson, U. J. (1985). Pediatric Research 19, 687-69I.

Glass, P., Avery, G. B., Siva Subramanian, K. N., Keys, M. P., Sostek, A. M. \& Friendly. D. S. (1985). New England Yournal of Medicine 313,401-404.

Haga, P., Ek, J. \& Kran, S. (1982). American Fournal of Clinical Nutrition 36, I 200-1 204.

Halliwell, B. \& Gutteridge, J. M. C. (1985a). Free Radicals in Biology and Medicine. Oxford: Oxford Lniversity Press.

Halliwell, B. \& Gutteridge, J. M. C. ( $\left.9^{8} 5_{5} b\right)$. Trends in Neurological Science 8, 22-26.

Hassan, H., Hashim, S. A., Van Itallie, T. B. \& Sebrell, W. H. (1966). American Journal of Clinical Nutrition r9, $147^{-1} 57$.

Hittner, H. M., Godio, L. B., Rudolph, A. J., Adams, J. M.. Garcia-Prats, J. A., Friedman, Z., Kautz, J. A. \& Monaco, W. A. (1981). New England Journal of Medicine 305, 1365-1371.

Johnson, L., Bowen, F. W., Abbasi, S., Herrmann, N.. Weston, M., Sacks, L.. Porat. R., Stahl, G., Peckham, G., Delivoria-Papadopoulos, M., Quinn, G. \& Schaffer, D. (1985). Pediatrics 75, $619-638$

Johnson, L., Schaffer, D. \& Boggs, T. R. Jr (1974). American Fournal of Clinical Nutrition 27, I I 58-II 73 .

Kinsey, V. E. (1956). Archives of Ophthalmology 56, 481-543.

Leonard, P. J., Doyle, E. \& Hartington, N. (1972). American Fournal of Clinical Nutrition 25, $480-484$. 
Lorch, V., Murphy, M. D., Hoersten, L. R., Harris, E., Fitzgerald, J. \& Sinha, S. N. (1985). Pediatrics 75, 598-602.

McCarthy, K., Bhogal, M., Nardi, M. \& Hart, D. (1984). Pediatric Research 18, $483-488$.

Merritt, T. A., Stuard, I. D., Puccia, J., Wood, B., Edwards, D. K., Finkelstein, J. \& Shapiro, D. L. ( $198 \mathrm{r})$. Journal of Pediatrics 98, 949-956.

Oski, F. A. \& Barness, L. A. (1967). Journal of Pediatrics 70, 21 1-220.

Owens, W. C. \& Owens, E. U. (1949). American fournal of Ophthalmology 32, 1631-1637.

Phelps, D. L. (1982). Pediatrics 70, 420-425.

Phelps, D. L. (1984). Pediatrics 74, II $14-1116$.

Phelps, D. L., Rosenbaum, A., I eake, R. D., Isenberg, S. \& Dorey, F. (1984). Pediatric Research $18,158 \mathrm{~A}$.

Riely, C. A., Cohen, G. \& Lieberman, M. (1974). Science 183, 208-2 ro.

Ritchie, J. H., Fish, M. B., McMasters, V. \& Grossman, M. (1968). New England fournal of Medicine 279, $1185^{-1190 .}$

Saldanha, R. L., Cepeda, E. E. \& Poland, R. L. (1980). Pediatric Research 14, 650.

Speer, M. E., Blifeld, C., Rudolph, A. J., Chadda, P., Holbein, M. E. B. \& Hittner, H. M. (1984). Pediatrics 74, 1107-1112.

Straumfjord, J. V. \& Quaife, M. I. (1946). Proceedings of the Society for Experimental Biology and Medicine 61, 369-371.

Terry, T. L. (1942). American fournal of Ophthalmology 25, 203-204.

Warshaw, J. B., Wilson, C. W., Saito, K. \& Prough, R. A. (1985). Pediatric Research 19, 81 9-823.

Wender, D. F., Thulin, G. E., Walker Smith, G. J. \& Warshaw, J. B. (198I). Pediatric Research $15,262-268$.

Wispc, J. R., Bell, E. F. \& Roberts, R. J. (1985). Pediatric Research 19, 374-379.

Wright, S. W., Filer, L. J. Jr \& Mason, K. E. (1951). Pediatrics 7, 386-393.

Yam, J., Frank, L. \& Roberts, R. J. (1978a). Proceedings of the Society for Experimental Biology and Medicine 157, 293-296.

Yam, J., Frank, L. \& Roberts, R. J. (1978b). Pediatric Research 12, I I5-119. 